\title{
Smartphone addiction is associated with symptoms of anxiety, depression, stress, tension, confusion, and insomnia: A cross-sectional and comparative study with physically and non-physically active adults in self-isolation during the COVID-19 pandemic
}

\author{
Luiz José Frota Solon Júnior, ${ }^{1}$ Carlos Henrique Tomaz Ribeiro, ${ }^{2}$ Leonardo de Sousa Fortes, ${ }^{3}$
}

Bruno Teixeira Barbosa, ${ }^{4}$ Luiz Vieira da Silva Neto ${ }^{2}$

\begin{abstract}
Universidade Federal do Ceará, Programa de Pós-Graduação em Biotecnologia, Sobral-Ceará, Brasil.

2 Universidade Estadual Vale do Acaraú, Centro de Ciências da Saúde. Sobral, Ceará, Brasil.

3 Universidade Federal da Paraíba, Departamento de Educação Física, João Pessoa, Paraíba, Brasil.

4 Centro Universitário de João Pessoa, Departamento de Educação Física, João Pessoa, Paraíba, Brasil.
\end{abstract}

\section{Correspondence:}

Luiz José Frota Solon Júnior

Universidade Federal do Ceará,

Programa de Pós-Graduação em

Biotecnologia.

Rua Menino Deus 500

Sobral-Ceará, Brasil.

Phone: +55 (088) 9.9688-1388

Email: sluis424@gmail.com

Received: 26 October 2020

Accepted: 27 January 2021

Citation:

Solon Júnior, L. J. F., Tomaz Ribeiro, C. H., de Sousa Fortes, L., Teixeira Barbosa, B., \& Vieira da Silva Neto, L. (2021). Smartphone addiction is associated with symptoms of anxiety, depression, stress, tension, confusion, and insomnia: A cross-sectional and comparative study with physically and non-physically active adults in self-isolation during the COVID-19 pandemic. Salud Mental, 44(4), 193-200.

DOI: $10.17711 /$ SM.0185-3325.2021.025

\begin{abstract}
Introduction. During the novel coronavirus disease (COVID-19) outbreak, social media exposure and the use of electronic devices have increased; still, these behaviors may cause adverse health effects. Objective. This study assessed sleep quality, insomnia, mood, and psychological aspects among physically $(n=46)$ and non-physically $(n=53)$ active individuals during self-isolation throughout the COVID-19 pandemic and examined their association with smartphone addiction. Method. A cross-sectional study was conducted among adult Brazilian citizens in self-isolation for at least 60 days; ninety-nine volunteers from different Brazilian regions were enrolled in the online survey. The Depression, Anxiety and Stress Scale-Short Form, the Pittsburgh Sleep Quality Index, the Insomnia Severity Index, the Brunel Mood Scale, and the Smartphone Addiction Scale-Short Version were used to assess the study outcomes. Results. The results indicate moderate and large correlations of smartphone addiction with mood subscales, insomnia $(r=.52)$, anxiety $(r=.49)$, depression $(r=.49)$, and stress $(r=.49)$ symptoms. Also, it was observed that physically active participants were less addicted to smartphones than the non-physically active during self-isolation $(p<.01)$ and that the physically active ones had a better mood and lower anxiety $(p=.02)$, depression $(p<.01)$ and insomnia $(p<.01)$ levels. Discussion and conclusion. These findings show the health implications of self-isolation and how essential it is to be physically active to avoid self-isolation's adverse psychological effects.
\end{abstract}

Keywords: Coronavirus, self-isolation, physical activity, addiction, psychological aspects.

\section{RESUMEN}

Introducción. Durante el brote de la nueva enfermedad por coronavirus (COVID-19), la exposición a los medios sociales y el uso de dispositivos electrónicos han aumentado; sin embargo, estos comportamientos pueden causar efectos adversos en la salud. Objetivo. Este estudio evaluó la calidad del sueño, el insomnio, el estado de ánimo y los aspectos psicológicos entre los individuos activos físicos $(n=46)$ y no físicos $(n=53)$ durante el autoaislamiento debido a la pandemia COVID-19 y examinó su asociación con la adicción a los teléfonos inteligentes. Método. Se llevó a cabo un estudio transversal entre ciudadanos brasileños adultos en autoaislamiento durante al menos 60 días; noventa y nueve voluntarios de diferentes regiones brasileñas se inscribieron en la encuesta en línea. La Depression, Anxiety and Stress Scale-Short Form, the Pittsburgh Sleep Quality Index, the Insomnia Severity Index, the Brunel Mood Scale, and the Smartphone Addiction Scale-Short Version se utilizaron para evaluar los resultados del estudio. Resultados. Los resultados indican correlaciones moderadas y mayores en la adicción a los teléfonos inteligentes con subescalas de humor, insomnio $(r=.52)$, síntomas ansiedad $(r=.49)$, depresión $(r=.49)$ y estrés $(r=.49)$. Además, se observó que los participantes físicamente activos eran menos adictos a los teléfonos inteligentes que los no activos durante el autoaislamiento $(p=.01)$ y que los físicamente activos tenían un mejor estado de ánimo y menores niveles de ansiedad $(p=.02)$, depresión $(p=.01)$ e insomnio $(p=.01)$. Discusión y conclusión. Estos hallazgos muestran las implicaciones para la salud del autoaislamiento y lo esencial que es ser físicamente activo para evitar los efectos psicológicos adversos del autoaislamiento.

Palabras clave: Coronavirus, autoaislamiento, actividad física, adicción, aspectos psicológicos. 


\section{INTRODUCTION}

Amid the growing concern, self-isolation was adopted by the World Health Organization to reduce coronavirus to spread out. Expressly, the first case of COVID-19 in Brazil was confirmed on February 26, and self-isolation was started on March 20 (Bull et al., 2020). Since social isolation has begun, several daily living activities are being performed at home (e.g., work and study). Nowadays, access to the internet is prevalent worldwide, and its use has been considered essential to get informed about health care and the COVID-19 pandemic (World Wide Web Foundation, 2020).

The increased internet access rate and social media addiction can adversely affect human behavior (Kircaburun \& Griffiths, 2018). During the COVID-19 pandemic, people have been submitted to higher exposure to social media, and this behavior change seems to be associated with mental disorders, such as anxiety and depression (Gao et al., 2020). Therefore, the higher exposure to social media suggests increased use of electronic devices, such as smartphones, which would be associated with other issues during the self-isolation period in the COVID-19 pandemic.

In the past few years, there has been an increase in smartphone users' numbers due to technological advances (Ictech, 2019). Still, some studies have shown that the excessive electronic devices use lead to adverse effects on physiological and psychological aspects, such as anxiety (Elhai, Levine, \& Hall, 2019), depression (Elhai, Yang, Fang, Bai, \& Hall, 2020), stress issues (Xu et al., 2019), and sleep (Chung et al., 2018). Other studies suggest that smartphone restriction could cause withdrawal symptoms and mood behavior changes (Eide, Aarestad, Andreassen, Bilder, \& Pallesen, 2018). Thus, we hypothesized that smartphone addiction during self-isolation in the COVID-19 pandemic is associated with psychological changes in adults.

Beyond being considered an effective strategy to improve mood, stress, anxiety, and depression (Mikkelsen, Stojanovska, Polenakovic, Bosevski, \& Apostolopoulos, 2017), exercise has been usually monitored and guided in the past few years with smartphones, which is essential considering the social isolation period (Jimoh et al., 2018). Previous studies have shown the benefits of exercising in sleep quality (Chennaoui, Arnal, Sauvet, \& Léger, 2015), even in patients with insomnia (D'Aurea et al., 2019). As it is known, physical exercise leads to beneficial effects on health and has been recommended to be performed at home during the current COVID-19 pandemic (Chen et al., 2020). So, we also hypothesize that physically active adults in self-isolation during the COVID-19 pandemic may report better mood and sleep quality, beyond lower levels of insomnia, stress, anxiety, and depression compared to the non-physically active ones.
So, the present study aimed to compare the psychological and sleep parameters among physically (i.e., those who kept exercising at home) and non-physically active adults during social isolation in the COVID-19 pandemic. The association of these health parameters with smartphone addiction was also assessed.

\section{METHOD}

\section{Design of the study}

This is an observational and cross-sectional study designed to compare psychological and sleep parameters among physically and non-physically active adults during the self-isolation period caused by the COVID-19 pandemic.

\section{Participants}

After performing the sample calculation 'A priori' in the $\mathrm{G}^{*}$ Power software (version 3.1.9), the number of participants in the study should be at least 90 subjects (Faul, Erdfelder, Lang, \& Buchner, 2007).

The inclusion criteria were: a) 18 to 30 years old; b) not with COVID-19 disease; c) male and female; d) in possesion of one or more smartphones. The exclusion criteria were: a) use of psychoactive drugs; b) history of psychiatric diseases; c) use of alcoholic beverages; d) not being in confinement since March 2020 until the data collection procedures day (June 2020). As an inclusion criterion for the physically active group, the participants should be practicing at least 150-300 minutes of moderate-intensity aerobic physical activity; or at least 75-150 minutes of vigorous-intensity aerobic physical activity (Bull et al., 2020). It is noteworthy that those in the physically active group should also be practicing physical activity before the self-isolation period for at least three times/week in the past six months. In the non-physically active group, only subjects who were not performing any physical exercise program since the beginning of the pandemic in Brazil were included.

One hundred and forty-nine people were interested in participating in the study; however, 50 participants were excluded for the following reasons: use of alcoholic beverages $(n=23)$, use of psychoactive drugs $(n=17), 20$ were not in self-isolation due to work, and 10 participants tested positive for COVID-19 during the study. After the eligibility criteria, only 99 subjects participated in the study, of which there were 44 males $(24.16 \pm 3.66 \mathrm{yrs}, 78.12 \pm 12.40 \mathrm{~kg}$, $173.52 \pm 7.87 \mathrm{~cm}$, and $\left.25.93 \pm 3.68 \mathrm{~kg} / \mathrm{m}^{2}\right)$ and 55 female $(23.58 \pm 4.17 \mathrm{yrs}, 59.41 \pm 9.69 \mathrm{~kg}, 160.44 \pm 5.25 \mathrm{~cm}$, and $\left.23.08 \pm 3.67 \mathrm{~kg} / \mathrm{m}^{2}\right)$.

It is noteworthy that, due to social distancing, body mass index (BMI) was calculated by weight and height 
self-reported by individuals. However, studies suggest that self-reported BMI may provide strongly correlated measures with cardiometabolic biomarkers (Lipsky et al., 2019), thus being an ideal measurement due to the social distancing recommended by the WHO.

\section{Procedures}

Volunteers were invited to enroll in the study through public invitation to participate in the study (e.g., social networks, electronic advertisement, etc) during the social isolation period in the COVID-19 pandemic. Those interested were contacted by telephone to be initially screened by the inclusion/exclusion criteria.

Researchers then sent a link through an e-mail with access to five questionnaires, as follows: Depression, Anxiety and Stress Scale-Short Form (Lovibond \& Lovibond, 1995), Pittsburgh Sleep Quality Index (Buysse, Reynolds, Monk, Berman, \& Kupfer, 1989), Insomnia Severity Index (Bastien, Vallières, \& Morin, 2001), Brunel Mood Scale (Rohlfs et al., 2008) and Smartphone Addiction Scale-Short Version (Kwon, Kim, Cho, \& Yang, 2013a).

\section{Measurements}

Depression, Anxiety, and Stress Scale-Short Form (DASS21). The DASS-21 (Lovibond \& Lovibond, 1995) was used in its (Vignola \& Tucci, 2014). It evaluates symptoms of depression, anxiety, and stress from the last week based on 21 items, which ranges from 0 (not applicable to me) to 3 (applies to me greatly, or most of the time). Scores above seven for anxiety, nine for depression, and 14 for stress are considered excessive for people who are not under psychiatric treatment (Sinclair et al., 2012). Internal consistency (i.e., Cronbach's alpha) among the volunteers in the scale of anxiety, depression, and stress were $.76, .89$, and .84, respectively (Landis \& Koch, 1977).

Pittsburgh Sleep Quality Index (PSQI). Self-reported sleep quality was evaluated based on the last four weeks during the self-isolation period through the Brazilian version of the PSQI (Buysse et al., 1989). Those who achieved a final score equal to or greater than five were considered bad sleepers (de Araujo et al., 2015). The Cronbach's alpha coefficient of the instrument was .28 among the volunteers (Landis \& Koch, 1977).

Insomnia Severity Index (ISI). The ISI was used to assess insomnia complaints in the last two weeks before data collection during the self-isolation period. The questionnaire consists of seven items and each one ranges from zero to four and may provide a total score from zero to 28 . The insomnia degree was determined according to the overall rating as an absence of insomnia (0-7), insomnia below the threshold (8-14), moderate insomnia (15-21), and severe insomnia (22-28) (Bastien et al., 2001). The internal consis- tency of the ISI questionnaire was .85 among the volunteers (Landis \& Koch, 1977).

Brunel Mood Scale (BRUMS) (Rohlfs et al., 2008). This is an instrument adapted from the "Profile of Mood States" (Mcnair, Lorr, \& Droppleman, 1971). The question used to assess the participants' mood during self-isolation was: "How did you feel last week, including today?." The BRUMS contains 24 items that may range from zero (nothing) to four (extremely) points each. The internal consistency of BRUMS (.92) and subscales separately were: anger (.95), confusion (.86), depression (.92), fatigue (.88), tension (.87), and vigour (.74) (Landis \& Koch, 1977).

Smartphone Addiction Scale-Short Version (SAS-SV). The Brazilian version of the SAS-SV was used to assess the severity of the problematic smartphone use (PSU) (Kwon et al., 2013b). The instrument consists of 10 items, which must be answered on a scale from one (totally disagree) to six (totally agree), with an overall score ranging from 10 to 60 points. Reaching 31 points (men) and 33 points (women) indicates the prevalence of PSU; that is, people with scores above these present indicators of addiction to smartphones (Kwon et al., 2013b). Cronbach's alpha of SAS-SV among volunteers was .89 (Landis \& Koch, 1977).

\section{Statistical analysis}

The sample size calculation was adopted a significance level of $p<.05$, a statistical power ( $\beta$ error) of .8 , and a Cohen's $\mathrm{d}$ (Cohen, 1988) effect size (ES) of .6 (criterion variable = smartphone addiction). The Kolmogorov Smirnov test was used to evaluate normality. Sex was used as a covariant for covariance analysis (ANCOVA) between groups, followed by the Bonferroni post hoc test. Pearson's test was used to assess the correlation between variables, and the correlation strength was adopted, as suggested by Cohen (1988). A simple linear regression model was performed to predict insomnia (dependent variable) based on smartphone addiction (independent variable) as a predictor (Kasza \& Wolfe, 2014). All data were obtained using the SPSS 26.0 program. Confidence intervals (CI) were constructed from $95 \%$ for the mean. Cronbach's alpha coefficient was performed to verify the instruments' reliability and internal consistency (Landis \& Koch, 1977). The effect size for the F ratio was expressed as partial eta-squared $\left(\eta^{2}\right)$.

\section{Ethical considerations}

This study has been approved by the Ethics Committee of the Universidade Estadual Vale do Acaraú (ID number 3.896.361) according to Standard 466/12 of the Brazils' National Health Council. The volunteers provided written consent in an online form, and all participants were informed about risks and benefits before filling the questionnaire through an online platform. 


\section{RESULTS}

The overall characteristics among the physically and non-physically active during self-isolation are described in Table 1.

The physically active group (20 male and 26 female) during self-isolation reported being engaged in weekly training ( $4.5 \pm 1.1$ days/week), with each training session lasting for $55.7 \pm 22.1$ (minutes) each training session. Physical exercise was commonly reported as being prescribed during self-isolation via videos on social media $(32.6 \%, n=15)$, online guidance by a personal trainer $(23.91 \%, n=11)$, and self-prescription $(43.47 \%, n=20)$. Volunteers in the non-physically active group (24 male and 29 female) were not exercising since the novel coronavirus outbreak in March 2020.

\section{Correlations}

Table 2 describes the moderate and large correlations between smartphone addiction (SAS-SV) and mood subscales (BRUMS), insomnia severity index (ISI), self-reported sleep quality (PSQI), and psychological symptoms (DASS21).

\section{Smartphone addiction}

The non-physically active group $(35.26 \pm 1.59 ; 95 \% \mathrm{CI}$ $[32.09,38.44])$ was considered as most addicted to electronic devices than the physically active one $(28.69 \pm 1.71$; $95 \% \mathrm{CI}=[25.28,32.09])\left(\mathrm{F}_{(1,96)}=7.866 ; p<.01 ; \beta\right.$ error $=$ $\left..79 ; \eta^{2}=.076\right)$.

\section{Anxiety, depression, and stress symptoms}

Figure 1 shows that stress in the physically active group $(12.34 \pm 1.19 ; 95 \% \mathrm{CI}=[9.97,14.71])$ was lower than in the non-physically active group $(15.43 \pm 1.11 ; 95 \% \mathrm{CI}=[13.22$, 17.64]), despite no statistical significance $\left(\mathrm{F}_{(1,96)}=3.583\right.$; $p=.061 ; \beta$ error $\left.=.47 ; \eta^{2}=.036\right)$. However, anxiety was shown to be statistically $\left(\mathrm{F}_{(1,96)}=5.378 ; p=.023 ; \beta\right.$ error $\left.=.63 ; \eta^{2}=.053\right)$ attenuated in the physically active group $(5.14 \pm .91 ; 95 \% \mathrm{CI}=[3.32,6.97])$ compared to the non-physically active one $(8.47 \pm 1.30 ; 95 \% \mathrm{CI}=[5.88$, $11.05])$. Still, the depressive symptoms were significantly lower $\left(\mathrm{F}_{(1,96)}=7.676 ; p=.007 ; \beta\right.$ error $\left.=.78 ; \eta^{2}=.074\right)$ in the physically active group $(8.47 \pm 1.30 ; 95 \% \mathrm{CI}=[5.88$, $11.05)$ than in the non-physically active $(13.40 \pm 1.21 ; 95 \%$ $\mathrm{CI}=[10.99,15.81])$.

\section{Mood}

Table 3 presents data from mood subscales between groups. The physically active group was reported as more vigor-
Table 1

Sample characteristics by groups

\begin{tabular}{lccrc}
\hline Variables & $\begin{array}{c}\text { Physically } \\
\text { active }(n=46)\end{array}$ & $\begin{array}{c}\text { Non-physically } \\
\text { active }(n=53)\end{array}$ & $F_{(1,96)}$ & \multicolumn{1}{c}{$p$} \\
\hline Age (years) & $24.65 \pm .57$ & $23.12 \pm .53$ & 3.795 & .054 \\
Weight $(\mathrm{kg})$ & $66.74 \pm 1.62$ & $68.59 \pm 1.51$ & .699 & .405 \\
Height $(\mathrm{cm})$ & $166.34 \pm .97$ & $166.17 \pm .90$ & .017 & .898 \\
BMI $\left(\mathrm{kg} / \mathrm{m}^{2}\right)$ & $23.94 \pm .65$ & $24.70 \pm .70$ & 1.047 & .309 \\
Days of & $65.12 \pm 2.13$ & $63.70 \pm 1.98$ & .239 & .626 \\
self-isolation & & & \\
\hline
\end{tabular}

Note: Values are expressed as means (standard deviation). Data were analyzed using analyses of covariance (using sex as a covariable).

$p<.05$ statistically significant.

Table 2

Correlation of SAS-SV with BRUMS, DASS-21, PSQI, and ISI

\begin{tabular}{llc}
\hline Variable & $r$ & $p$ \\
\hline BRUMS & & \\
Fatigue & $.463^{*}$ & $<.001$ \\
Tension & $.553^{* *}$ & $<.001$ \\
Depression & $.460^{*}$ & $<.001$ \\
Vigour & $-.333^{*}$ & $<.001$ \\
Confusion & $.567^{* *}$ & $<.001$ \\
Anger & $.439^{*}$ & $<.001$ \\
DASS-21 & & \\
Stress & $.490^{*}$ & $<.001$ \\
Anxiety & $.496^{*}$ & $<.001$ \\
Depression & $.495^{*}$ & $<.001$ \\
PSQI & $.389^{*}$ & $<.001$ \\
ISI & $.524^{* *}$ & $<.001$ \\
\hline
\end{tabular}

Note: BRUMS: Brunel Mood Scale; DASS-21: Depression, Anxiety and Stress Scale - Short Form; PSQI: Pittsburgh Sleep Quality Index; ISI: Insomnia Severity Index; SAS-SV: Smartphone Addiction Scale-Short Version. ${ }^{*} r=$ Moderate correlation; ${ }^{*} r=$ Large correlation.

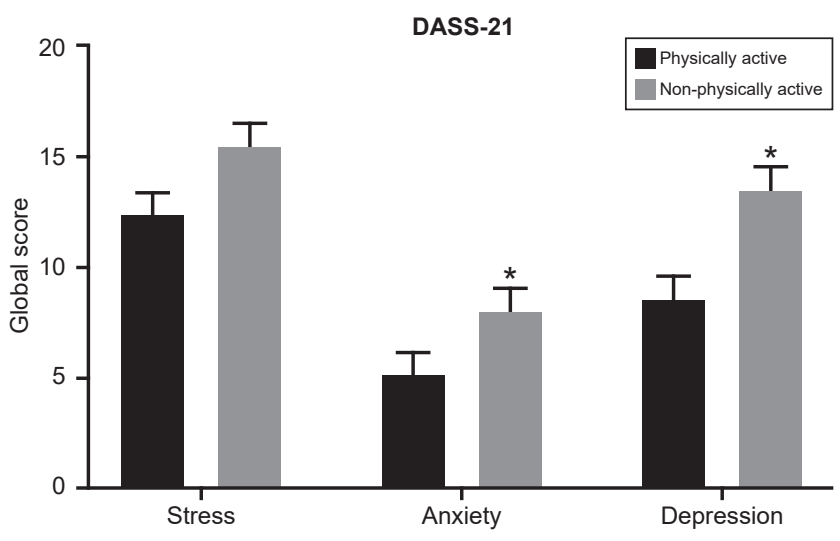

Figure 1. Scores of anxiety, depression, and stress.

Note: Values are expressed as means (standard deviation). Data were analyzed using analysis of covariance (using sex as a covariable). DASS-21: Depression, Anxiety, and Stress Scale - Short Form. ${ }^{*} p<.05$ statistically significant. 
Table 3

The mood of physically active subjects compared to non-active individuals

\begin{tabular}{|c|c|c|c|c|c|c|c|}
\hline \multirow{2}{*}{$\frac{\text { Subscale }}{\text { Tension }}$} & \multicolumn{2}{|c|}{$\begin{array}{c}\text { Active } \\
(n=46)\end{array}$} & \multicolumn{2}{|c|}{$\begin{array}{c}\text { Non-active } \\
(n=53)\end{array}$} & \multirow{2}{*}{$\frac{F_{(1,96)}}{2.720}$} & \multirow{2}{*}{$\frac{p}{.102}$} & \multirow{2}{*}{$\frac{\eta^{2}}{.028}$} \\
\hline & $5.62 \pm .56$ & $(4.49-6.75)$ & $6.90 \pm .90$ & $(5.85-7.96)$ & & & \\
\hline Fatigue & $4.56 \pm .61$ & $(3.34-5.78)$ & $7.54 \pm .57^{*}$ & $(6.41-8.68)$ & 12.632 & .001 & .116 \\
\hline Depression & $3.07 \pm .58$ & $(1.92-4.23)$ & $5.08 \pm .54^{*}$ & $(4.00-6.15)$ & 6.363 & .013 & .062 \\
\hline Vigor & $8.93 \pm .46$ & $(8.03-9.86)$ & $6.13 \pm .42^{*}$ & $(5.28-6.98)$ & 19.993 & .001 & .172 \\
\hline Confusion & $4.25 \pm .55$ & $(3.15-5.36)$ & $6.53 \pm .51^{*}$ & $(5.50-7.55)$ & 8.936 & .004 & .085 \\
\hline Anger & $4.30 \pm .69$ & $(2.92-5.68)$ & $6.37 \pm .64^{*}$ & $(5.08-7.66)$ & 4.719 & .032 & .047 \\
\hline
\end{tabular}

Note: Values are expressed as means (standard deviation). Data were analyzed using analysis of covariance (using sex as a covariable). ${ }^{*} p<.05$ statistically significant.

ous and less fatigued than the non-physically group. Additionally, the results suggest higher scores for depression, confusion, and anger for the non-physically active group compared to the physically active one.

\section{Sleep quality and insomnia}

In Figure 2, both physically $(7.91 \pm .39 ; 95 \%$ CI [7.14, $8.69])$ and non-physically active $(8.84 \pm .36$; 95\% CI [8.12, 9.56]) groups were considered poorer sleepers (global scores $\geq 5$ ), but no significant difference between the groups $\left(\mathrm{F}_{(1,96)}=3.021 ; p=.085 ; \beta\right.$ error $\left.=.41 ; \eta^{2}=.031\right)$ were observed. However, analyses have shown significant differences $\left(\mathrm{F}_{(1,96)}=7.732, p=.007 ; \beta\right.$ error $\left.=.79 ; \eta^{2}=.075\right)$ between the physically $(8.76 \pm 0.92 ; 95 \%$ CI $[6.93,10.60])$ and non-physically active (12.27 $\pm .86 ; 95 \%$ CI [10.57, 13.98]) groups for insomnia severity index.

Insomnia also seems to be associated with stress $(r=.67$, $p<.001)$, anxiety $(r=.60, p<.001)$ and depression $(r=.55$, $p<.001)$ symptoms. In some mood state subscales, such as fatigue $(r=.64, p<.001)$, confusion $(r=.61, p<.001)$, and tension $(r=.58, p<.001)$, large correlations with insomnia were verified.

Simple linear regression analysis resulted in a statistically significant model $\left[\mathrm{F}_{(1.97)}=36.644 ; p<.001 ; \mathrm{R}^{2} .274\right]$ and

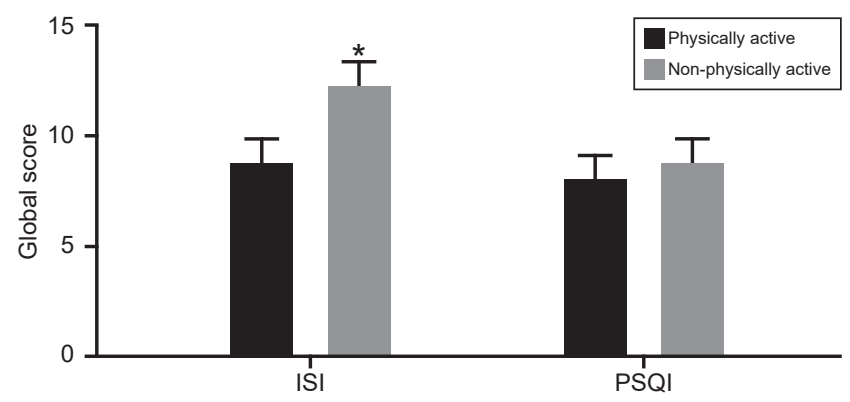

Figure 2. Scores of ISI and PSQI scores.

Note. Values are expressed as means (standard deviation). Data were analyzed using analysis of covariance (using sex as a covariable). ISI: Insomnia Severity Index; PSQI: Pittsburgh Sleep Quality Index. * $p<.05$ statistically significant. has demonstrated that the smartphone addiction $(p<.001)$ is a positive predictor for insomnia.

\section{DISCUSSION AND CONCLUSION}

The main findings of the present study suggest that the physically active adults during the COVID-19 pandemic were less addicted to smartphones than those non-physically active, and this addiction was positively correlated with anxiety, depression, and stress. Still, the physically active volunteers presented lower levels of insomnia compared to the non-physically active ones. Besides, insomnia has demonstrated being positively associated with stress, anxiety, and depressive symptoms.

Exercise and addiction to electronic devices may play a similar role in neurophysiological mechanisms usually associated with reward (Liu, Xiao, Yang, \& Loprinzi, 2019). During the COVID-19 pandemic, this addiction has increased (Gao et al., 2020) and, in this sense, physical exercise may lead to brain alteration and has been shown as a strategy to attenuate the addiction behavior (Weinstein \& Lejoyeux, 2015), which may be helpful in current days where social isolation is required.

During the COVID-19 pandemic, an increased exposure to social media, took place which is be associated with mental health problems (Gao et al., 2020). Despite the importance and growth of social media in the past years and a large amount of information available from that growth, mental health seems to have been negatively affected (Bao, Sun, Meng, Shi, \& Lu, 2020; Roth \& Brönnimann, 2013). So, exercising, even at home, must be recommended during the social isolation caused by the COVID-19 pandemic to reduce smartphone addiction and attenuate anxiety, depression, and stress levels (Mikkelsen et al., 2017; Solon Júnior et al., 2020).

Mood, especially tension and confusion, was associated with smartphone addiction during self-isolation during the COVID-19 pandemic. These findings were more recently confirmed in undergraduate students (Grimaldi-Puyana, 
Fernández-Batanero, Fennell, \& Sañudo, 2020), despite not being assessed during the COVID-19 pandemic. Still, previous recent studies have stated that changes in mood behavior have happened as a result of the social isolation caused by the current pandemic (Brietzke, Magee, Freire, Gomes, \& Milev, 2020; Troyer, Kohn, \& Hong, 2020). So, and based on the present findings, we hypothesized that smartphones might be one factor associated with these adverse effects on mood behavior.

Grimaldi-Puyana et al. (2020) also observed that young undergraduate students with low levels of physical activity are more likely to present increased time spent on smartphones. In this sense, our findings suggest that those considered physically active during the COVID-19 pandemic reported feeling more vigorous and being less fatigued, not to speak of presenting lower symptoms of depression, confusion, and anger. This being said, a previous study showed that physically active individuals presented less fatigue compared to the non-physically active ones (Engberg, Segerstedt, Waller, Wennberg, \& Eliasson, 2017). Moreover that, recent studies pointed out at exercising has been an efficient tool to improve mood (Haider, Grabovac, Rieder, \& Dorner, 2019) and self-confidence (Peluso \& Guerra de Andrade, 2005).

Our study showed moderate to large correlations between smartphone addiction and self-reported sleep quality and insomnia severity indexes. Smartphone use just before get sleep impairs sleep hygiene and induces the individual to poor sleep quality and insomnia episodes (Exelmans \& Van den Bulck, 2016). These harmful consequences may be explained by the exposure to the smartphone light that can emit short wavelengths, which can decrease for hours the production of melatonin, considered an essential hormone for the biological regulation of sleep.

Furthermore, a recent study ran during the COVID-19 pandemic pointed out that worry, loneliness, and depression symptoms are predictors of insomnia (Voitsidis et al., 2020). In our findings, it was found that smartphone addiction has also been a predictor of insomnia during the self-isolation period in the COVID-19 pandemic. In this sense, an increase in therapeutic interventions such as home-based exercise must be considered to support people to deal with insomnia issues during social isolation periods.

As far as we know, this is the first study to present homebased exercise as being an effective strategy to decrease insomnia during self-isolation. Previous studies have already described the positive effects of moderate intensity aerobic exercise (Passos et al., 2011) and resistance training and stretching (D'Aurea et al., 2019) in individuals with insomnia. Although the mechanisms that underline sleep quality improvements caused by exercise remain unclear (Kovacevic, Mavros, Heisz, \& Fiatarone Singh, 2018), home-based exercise must be considered an essential non-pharmacological strategy during a self-isolation period to improve sleep parameters (Solon Júnior et al., 2020).
Although the present study analyzed a relatively smaller number of participants than others (Yang \& Koenigstorfer, 2020), the sample size of this study was appropriate for statistical observations. It is also noteworthy that, unlike other studies (Yang \& Koenigstorfer, 2020), sociodemographic information (e.g., educational level, marital status, personal annual gross income, and employment status) was not collected, which could be considered as a limiting factor of the study. In addition, due to social confinement, we did not use gold-standard methods to evaluate sleep quality, such as polysomnography. However, similar to PSQI, all other instruments used in this study have scientific validation and accuracy. It is noteworthy that all research was conducted online, and all data were self-reported by the participants, that is to say, there was no intervention by the researchers. Although it might be considered a limitation, the researchers gave all the necessary information and support to the participants. However, this methodology (online research) has been commonly used during the pandemic period (Gao et al., 2020) to prevent the spread of the virus (Bull et al., 2020).

In conclusion, our results suggest that smartphone use during self-isolation periods is associated with vigor changes, fatigue, tension, confusion, self-reported sleep quality, insomnia, anxiety, depression, and stress symptoms. We also verified that keeping physically active by home-based exercise may attenuate smartphone addiction and improve anxiety, depression, and insomnia symptoms. Additionally, keeping exercising has shown to be beneficial to mood behavior and psychological aspects during self-isolation. Thus, it becomes essential to include physical exercise at home during the period of self-isolation to improve mental health. Based on the findings of this study, educational actions can be implemented to promote the practice of physical exercise at home, usually because it is not known when the current pandemic will end or when the world will go through other future pandemics.

\section{Funding}

None.

\section{Conflict of interest}

The authors declare they have no conflicts of interest.

\section{Acknowledgments}

The Coordenação de Aperfeiçoamento de Pessoal de Nível Superior-CAPES. The researchers of the study would like to thank all the participants who offered to take part in this study.

\section{REFERENCES}

Bao, Y., Sun, Y., Meng, S., Shi, J., \& Lu, L. (2020). 2019-nCoV epidemic: address mental health care to empower society. The Lancet, 395(10224), e37-e38. doi: 10.1016/S0140-6736(20)30309-3

Bastien, C. H., Vallières, A., \& Morin, C. M. (2001). Validation of the Insomnia Severity Index as an outcome measure for insomnia research. Sleep Medicine, 2(4), 297-307. doi: 10.1016/S1389-9457(00)00065-4 
Brietzke, E., Magee, T., Freire, R. C. R., Gomes, F. A., \& Milev, R. (2020). Three insights on psychoneuroimmunology of mood disorders to be taken from the COVID-19 pandemic. Brain, Behavior, \& Immunity - Health, 5, 100076. doi: 10.1016/j.bbih.2020.100076

Bull, F. C., Al-Ansari, S. S., Biddle, S., Borodulin, K., Buman, M. P., Cardon, G... Willumsen, J. F. (2020). World Health Organization 2020 guidelines on physical activity and sedentary behaviour. British Journal of Sports Medicine, 54(24), 1451-1462. doi: 10.1136/bjsports-2020-102955

Buysse, D. J., Reynolds, C. F., Monk, T. H., Berman, S. R., \& Kupfer, D. J. (1989). The Pittsburgh Sleep Quality Index: A new instrument for psychiatric practice and research. Psychiatry Research, 28(2), 193-213. doi: 10.1016/01651781(89)90047-4

Chen, P., Mao, L., Nassis, G. P., Harmer, P., Ainsworth, B. E., \& Li, F. (2020). Coronavirus disease (COVID-19): The need to maintain regular physical activity while taking precautions. Journal of Sport and Health Science, 9(2), 103-104. doi: 10.1016/j.jshs.2020.02.001

Chennaoui, M., Arnal, P. J., Sauvet, F., \& Léger, D. (2015). Sleep and exercise: A reciprocal issue? Sleep Medicine Reviews, 20, 59-72. doi: 10.1016/j. smrv.2014.06.008

Chung, J. E., Choi, S. A., Kim, K. T., Yee, J., Kim, J. H., Seong, J. W., ... Gwak, H. S. (2018). Smartphone addiction risk and daytime sleepiness in Korean adolescents. Journal of Paediatrics and Child Health, 54(7), 800-806. doi: 10.1111/jpc. 13901

Cohen, J. (1988). Statistical power analysis for the behavioral sciences, 2nd ed. (pp. 1-490). Retrieved from https://books.google.es/books?id=rEe0BQAAQBAJ\&d $\mathrm{q}=$ Statistical+power+analysis + for + the + behavioral + sciences $+(2 \mathrm{nd}+\mathrm{ed}) \& .1 \mathrm{r}=\&$ $\mathrm{hl}=$ es\&source $=\mathrm{gbs} \_$navlinks_s

de Araujo, P. A. B., Sties, S. W., Wittkopf, P. G., Netto, A. S., Gonzáles, A. I., Lima, D. P., ...de Carvalho, T. (2015). Índice Da Qualidade Do Sono De Pittsburgh Para Uso Na Reabilitação Cardiopulmonar E Metabólica. Revista Brasileira de Medicina Do Esporte, 21(6), 472-475. doi: 10.1590/1517869220152106147561

D’Aurea, C. V. R., Poyares, D., Passos, G. S., Santana, M. G., Youngstedt, S. D., Souza, A. A., ... de Mello, M. T. (2019). Effects of resistance exercise training and stretching on chronic insomnia. Revista Brasileirade Psiquiatria, 41(1), 5157. doi: 10.1590/1516-4446-2018-0030

Eide, T. A., Aarestad, S. H., Andreassen, C. S., Bilder, R. M., \& Pallesen, S. (2018). Smartphone restriction and its effect on subjective withdrawal related scores. Frontiers in Psychology, 9(1444), 1-11. doi: 10.3389/fpsyg.2018.01444

Elhai, J. D., Levine, J. C., \& Hall, B. J. (2019). The relationship between anxiety symptom severity and problematic smartphone use: A review of the literature and conceptual frameworks. Journal of Anxiety Disorders, 62, 45-52. doi: 10.1016/j.janxdis.2018.11.005

Elhai, J. D., Yang, H., Fang, J., Bai, X., \& Hall, B. J. (2020). Depression and anxiety symptoms are related to problematic smartphone use severity in Chinese young adults: Fear of missing out as a mediator. Addictive Behaviors, 101, 105962. doi: 10.1016/j.addbeh.2019.04.020

Engberg, I., Segerstedt, J., Waller, G., Wennberg, P., \& Eliasson, M. (2017). Fatigue in the general population- associations to age, sex, socioeconomic status, physical activity, sitting time and self-rated health: the northern Sweden MONICA study 2014. BMC Public Health, 17, 654. doi: 10.1186/s12889-017-4623-y

Exelmans, L., \& Van den Bulck, J. (2016). Bedtime mobile phone use and sleep in adults. Social Science \& Medicine, 148, 93-101. doi: 10.1016/j. socscimed.2015.11.037

Faul, F., Erdfelder, E., Lang, A-G., Buchner, A. (2007). G*Power 3: A flexible statistical power analysis program for the social, behavioral, and biomedical sciences. Behavior Research Methods, 39(2), 175-91. doi: 10.3758/bf03193146.

Gao, J., Zheng, P., Jia, Y., Chen, H., Mao, Y., Chen, S., ... Dai, J. (2020). Mental health problems and social media exposure during COVID-19 outbreak. PLoS ONE, 15(4), e0231924. doi: 10.1371/journal.pone.0231924

Grimaldi-Puyana, M., Fernández-Batanero, J. M., Fennell, C., \& Sañudo, B. (2020). Associations of objectively-assessed smartphone use with physical activity, sedentary behavior, mood, and sleep quality in young adults: A cross-sectional study. International Journal of Environmental Research and Public Health, 17(10), 3499. doi: 10.3390/ijerph17103499
Haider, S., Grabovac, I., Rieder, A., \& Dorner, T. E. (2019). Depressive symptoms, lack of physical activity, and their combination towards health care utilisation frequency. International Journal of Environmental Research and Public Health, 16(23), 4697. doi: 10.3390/ijerph16234697

Ictech, B. (2019). Smartphones and Face-to-Face Interaction: Digital Cross-Talk During Encounters in Everyday Life. Symbolic Interaction, 42(1), 27-45. doi: 10.1002/symb.406

Jimoh, F., Lund, E. K., Harvey, L. J., Frost, C., Lay, W. J., Roe, M. A., ... Finglas, P. M. (2018). Comparing diet and exercise monitoring using smartphone app and paper diary: A two-phase intervention study. JMIR mHealth and uHealth, 6(1), e17. doi: 10.2196/mhealth.7702

Kasza, J., \& Wolfe, R. (2014). Interpretation of commonly used statistical regression models. Respirology, 19(1), 14-21. doi: 10.1111/resp.12221

Kircaburun, K., \& Griffiths, M. D. (2018). Instagram addiction and the Big Five of personality: The mediating role of self-liking. Journal of Behavioral Addictions, 7(1), 158-170. doi: 10.1556/2006.7.2018.15

Kovacevic, A., Mavros, Y., Heisz, J. J., \& Fiatarone Singh, M. A. (2018). The effect of resistance exercise on sleep: A systematic review of randomized controlled trials. Sleep Medicine Reviews, 39, 52-68. doi: 10.1016/j.smrv.2017.07.002

Kwon, M., Kim, D.-J., Cho, H., \& Yang, S. (2013a). The smartphone addiction scale: Development and validation of a short version for adolescents. PLOS ONE, 8(12), e83558. doi: 10.1371/journal.pone.0083558

Kwon, M., Lee, J.-Y., Won, W.-Y., Park, J.-W., Min, J.-A., Hahn, C., ... Kim, D.-J. (2013b). Development and Validation of a Smartphone Addiction Scale (SAS). PLoS ONE, 8(2), e56936. doi: 10.1371/journal.pone.0056936

Landis, J. R., \& Koch, G. G. (1977). The Measurement of Observer Agreement for Categorical Data. Biometrics, 33(1), 159-174. doi: 10.2307/2529310

Lipsky, L. M., Haynie, D. L., Hill, C., Nansel, T. R., Li, K., Liu, D., ... SimonsMorton, B. (2019). Accuracy of Self-Reported Height, Weight, and BMI Over Time in Emerging Adults. American Journal of Preventive Medicine, 56(6), 860-868. doi:10.1016/j.amepre.2019.01.004

Liu, S., Xiao, T., Yang, L., \& Loprinzi, P. D. (2019). Exercise as an alternative approach for treating smartphone addiction: A systematic review and metaanalysis of random controlled trials. International Journal of Environmental Research and Public Health, 16(20), 3912. doi: 10.3390/ijerph16203912

Lovibond, P. F., \& Lovibond, S. H. (1995). The structure of negative emotional states: Comparison of the Depression Anxiety Stress Scales (DASS) with the Beck Depression and Anxiety Inventories. Behaviour Research and Therapy, 33(3), 335-343. doi: 10.1016/0005-7967(94)00075-U

Mcnair, D. M., Lorr, M., \& Droppleman, L. F. (1971). Manual for the Profile of Mood States. San Diego, CA: Educational and Industrial Testing Services. Retrieved from https://www.statisticssolutions.com/profile-of-mood-states-poms/

Mikkelsen, K., Stojanovska, L., Polenakovic, M., Bosevski, M., \& Apostolopoulos, V. (2017). Exercise and mental health. Maturitas, 106, 48-56. doi: 10.1016/j. maturitas.2017.09.003

Passos, G. S., Poyares, D., Santana, M. G., D’Aurea, C. V. R., Youngstedt, S. D., Tufik, S., \& de Mello, M. T. (2011). Effects of moderate aerobic exercise training on chronic primary insomnia. Sleep Medicine, 12(10), 1018-1027. doi: 10.1016/j.sleep.2011.02.007

Peluso, M. A. M., \& Guerra de Andrade, L. H. S. (2005). Physical activity and mental health: the association between exercise and mood. Clinics (São Paulo, Brazil), 60(1), 61-70. doi: 10.1590/S1807-59322005000100012

Rohlfs, I. C. P. D. M., Rotta, T. M., Luft, C. D. B., Andrade, A., Krebs, R. J., \& De Carvalho, T. (2008). Brunel mood scale (BRUMS): An instrument forearly detectionof overtraining syndrome. Revista Brasileira de Medicina Do Esporte, 14(3), 176-181. doi: 10.1590/S1517-86922008000300003

Roth, F., \& Brönnimann, G. (2013). Focal Report 8: Risk Analysis Using the Internet for Public Risk Communication (pp. 5-24). Risk and Resilience Research Group, Center for Security Studies (CSS), ETH Zürich. Retrieved from https://www. research-collection.ethz.ch/bitstream/handle/20.500.11850/73314/eth-7416-01.pdf

Sinclair, S. J., Siefert, C. J., Slavin-Mulford, J. M., Stein, M. B., Renna, M., \& Blais, M. A. (2012). Psychometric Evaluation and Normative Data for the Depression, Anxiety, and Stress Scales-21 (DASS-21) in a Nonclinical Sample of U.S. Adults. Evaluation \& the Health Professions, 35(3), 259-279. doi: $10.1177 / 0163278711424282$ 
Solon Júnior, L. J. F., Fortes, L. S., Barbosa, B. T., Feitosa Júnior, J. V. A., Ribeiro, C. H. T., \& Silva Neto, L. V. (2020). Home-based exercise during confinement in CO-VID-19 pandemic and mental health in adults: a cross-sectional comparative study. Revista Brasileira de Atividade Fisica \& Saúde, 25, 1-7. doi: $10.12820 /$ rbafs. $25 \mathrm{e} 0120$

Troyer, E. A., Kohn, J. N., \& Hong, S. (2020). Are we facing a crashing wave of neuropsychiatric sequelae of COVID-19? Neuropsychiatric symptoms and potential immunologic mechanisms. Brain, Behavior, and Immunty, 87, 34-39. doi: 10.1016/j.bbi.2020.04.027

Vignola, R. C. B., \& Tucci, A. M. (2014). Adaptation and validation of the depression, anxiety and stress scale (DASS) to Brazilian Portuguese. Journal of Affective Disorders, 155, 104-109. doi: 10.1016/j.jad.2013.10.031

Voitsidis, P., Gliatas, I., Bairachtari, V., Papadopoulou, K., Papageorgiou, G., Parlapani, E., ... Diakogiannis, I. (2020). Insomnia during the COVID-19 pandemic in a Greek population. Psychiatry Research, 289, 113076. doi: 10.1016/j.psychres.2020.113076
Weinstein, A., \& Lejoyeux, M. (2015). New developments on the neurobiological and pharmaco-genetic mechanisms underlying internet and videogame addiction. American Journal on Addictions, 24(2), 117-125. doi: 10.1111/ajad.12110

World Wide Web Foundation. (2020). The web can help more in the fight against Covid-19. Here's what we must do. News and Blogs. Retrieved from https:// webfoundation.org/2020/03/the-web-can-help-more-in-the-fight-against-covid19-heres-what-we-must-do/

Xu, T. T., Wang, H. Z., Fonseca, W., Zimmerman, M. A., Rost, D. H., Gaskin, J., \& Wang, J. L. (2019). The relationship between academic stress and adolescents' problematic smartphone usage. Addiction Research \& Theory, 27(2), 162-169. doi: 10.1080/16066359.2018.1488967

Yang, Y., \& Koenigstorfer, J. (2020). Determinants of physical activity maintenance during the Covid-19 pandemic: a focus on fitness apps. Translational Behavioral Medicine, 10(4), 835-842. doi: 10.1093/tbm/ibaa086 